\title{
Autosomal recessive inherited bleeding disorders in Pakistan: a cross-sectional study from selected regions
}

\author{
Arshi Naz ${ }^{1 *}$ D, Muhammad Younus Jamal', Samina Amanat ${ }^{2}$, Ikram Din ujjan ${ }^{3}$, Akber Najmuddin $^{4}$, Humayun Patel ${ }^{1}$, \\ Fazle Raziq ${ }^{5}$, Nisar Ahmed ${ }^{6}$, Ayisha Imran $^{7}$ and Tahir Sultan Shamsi ${ }^{1}$
}

\begin{abstract}
Background: Autosomal recessive bleeding disorders (ARBDs) include deficiencies of clotting factors I, II, V, VII, X, XI, XIII, vitamin K dependent clotting factors, combined factor V \& VIII, Von Willebrand Disease (VWD) type 3, Glanzmann's thrombasthenia (GT) and Bernard-Soulier syndrome. Patients with primary bleeding disorders from all the major provincial capitals of Pakistan were screened for ARBDs. Prothrombin (PT), activated partial thromboplastin time (APTT), bleeding time (BT) and fibrinogen levels were measured. Cases with isolated prolonged APTT were tested for factors VIII and IX using factor assays This was followed by FXI:C level assessment in cases with normal FVIII and FIX levels. VWD was screened in patients with low FVIII levels. Factors $\mathrm{II}, \mathrm{V}$ and $\mathrm{X}$ were tested in patients with simultaneous prolongation of PT and APTT. Peripheral blood film examination and platelet aggregation studies were performed to assess platelet disorders. Urea clot solubility testing was done to detect Factor XIII levels where platelet function tests were normal. Descriptive analysis was done using SPSS version 16.

Results: Of the 429 suspected bleeding disorder patients, 148 (35\%) were diagnosed with hemophilia A and $211(49.1 \%)$ patients had ARBDs. 70 patients (16.3\%) remained undiagnosed. Out of 211 patients with ARBD; 95 (33.8\%) had VWD type 3. Fibrinogen deficiency was found in 34 patients (12\%), GT in 27 (9.6\%), factor XIII deficiency in 13 (4.6\%), factor VII deficiency in 12 (4.3\%), factor V deficiency in 9 (3.2\%). Eight patients (2.8\%) had vitamin K-dependent clotting factor deficiency, Bernard-Soulier syndrome was diagnosed in seven patients (2. $5 \%)$, factor $X$ deficiency in $2(0.7 \%)$, factor II deficiency in $2(0.7 \%)$, factor XI deficiency and combined factor $V$ and VIII deficiency in $1(0.4 \%)$ patient each.
\end{abstract}

Conclusion: VWD type 3 was the most common ARBD found in our sample of patients in Pakistan, followed by fibrinogen deficiency and GT in respective order.

Keywords: Autosomal recessive, Inherited bleeding disorders, Coagulation factors, von Willebrand disease type 3, Glanzmann's thrombasthenia, Bernard-Soulier syndrome

\section{Background}

The incidence of autosomal recessive bleeding disorders (ARBDs) worldwide is uncommon at about $3-5 \%$ $[1,2]$ as compared with other causes of bleeding. However, these disorders predominate in those regions of the world where consanguineous marriages are encouraged [3]. Pakistan has a high rate of such

\footnotetext{
* Correspondence: labarshi2013@gmail.com; labarshi@yahoo.com

${ }^{1}$ Department of Thrombosis and Hemostasis, National Institute of Blood Diseases and Bone Marrow Transplantation, ST 2/A, Block 17, Gulshan-e-lqbal, KDA Scheme 24, Karachi, Pakistan

Full list of author information is available at the end of the article
}

marriages $[4,5]$. The prevalence of some of these disorders in the local population has only been reported in a few studies [6-11] and a lack of diagnostic facilities and expertise has prevented a comprehensive study to identify ARBDs.

The ARBDs include deficiencies of clotting factors I, II, V, VII, X, XI, XIII, vitamin K-dependent clotting factors [VKDCF; II, VII, IX and X], combined factors $\mathrm{V}$ and VIII, von Willebrand disease type 3 (vWD), Glanzmann's thrombasthenia (GT) and Bernard-Soulier syndrome (BSS). The presentation and bleeding 
pattern in these patients varies according to the etiology of each disorder [12, 13]. Life threatening bleeding episodes e.g., central nervous system or musculoskeletal bleeding, occur rarely.

Fibrinogen deficiency has a prevalence of 1 in a million $[14,15]$. It is subdivided into two distinct phenotypes: quantitative defect (afibrinogenemia and hypofibrinogenemia) and qualitative defect (dysfibrinogenemia and hypodysfibrinogenemia), Prothrombin deficiency (PD) has a prevalence of approximately 1 in two million [16] and has two phenotypes: true hypoprothrombinemia (type I deficiency) and dysprothrombinemia (type II deficiency) [16]. Factor V [FV] deficiency is manifested by skin and mucus membrane bleeding, epistaxis and menorrhagia. Prevalence is 1 in a million [17]. Factor VII deficiency presents as a hemophilia-like bleeding disorder with an estimated prevalence of 1 in 300,000-500,000 [18]. The most severe form of $\mathrm{vWD}$ is type 3 , characterized by a bleeding disorder associated with a total or near-total absence of von Willebrand factor (vWF) with deficiency of plasmatic factor VIII (FVIII) [8]. The type 3 $\mathrm{vW}$ disease is the rarest form of $\mathrm{vWD}$, accounting for less than $5 \%$ of all cases of bleeding disorders worldwide. Annual incidence ranges from 1 in two million to 1 in 350,000 in Europe and the United States, with estimates of around 1 per 500,000 in countries where consanguinity is more frequent [19]. Combined deficiency of factor $\mathrm{V}$ and VIII is associated with mutations in the LMAN1 and MCFD2 genes [20, 21]. It is characterized by concomitantly low levels (usually between 5 and 20\%) of both FV and FVIII and is associated with a mild to moderate bleeding tendency [22]. There are two variants to vitamin K-dependent clotting factor deficiency VKDCF; VKDCF1, associated with point mutations in the gamma-glutamyl carboxylase gene (GGCX), and VKDCF2, which results from point mutations in the vitamin $\mathrm{K}$ epoxide reductase gene (VKORC1) [23]. Factor X deficiency has an estimated prevalence of 1 in one million individuals [24]. Factor XI deficiency can manifest first as a bleeding disorder or as an incidental laboratory abnormality. Occurrence is approximately 1 per one million [25]. Factor XIII deficiency is a rare disorder, causing a severe bleeding tendency. The incidence is 1 per one million to 1 in five million people $[26,27]$. GT is the most frequently diagnosed inherited disorder of platelet function (prevalence, 1 in a million) [28]. Patients lack or have nonfunctional alpha $2 b$ beta $3(\alpha \operatorname{IIb} \beta 3)$ integrin. Type I individuals have $<5 \%$ of $\alpha \operatorname{IIb} \beta 3$, while type II have between 10 and $20 \%$. In type III, there are normal levels of $\alpha \operatorname{IIb} \beta 3$, but they are not functional [29]. The autosomal recessive disorder BSS has a prevalence of 1 in one million [30]. Platelets from patients with BSS lack the major surface membrane glycoprotein complex, glycoprotein (GP) Ib-IX-V [31].

The aim of this study was to determine and compare the 12 year period prevalence of ARBDs in several regions of Pakistan.

\section{Methods}

The study was approved by the ethics committee of the National Institute of Blood Diseases and Bone Marrow Transplantation (NIBD), Karachi, Pakistan, in accordance with the declaration of Helsinki. It was a descriptive study with cross-sectional time prospect, conducted from March 2010 till December 2014.

In local set-up, patients are usually diagnosed to have a bleeding disorder at primary and secondary health care centers or general clinics. The confirmatory investigations usually include only the platelets count, bleeding time (BT), Prothrombin time (PT) and activated partial thromboplastin time (APTT). Such cases are hence labelled as merely the bleeding disorder patients. These centers and clinics were asked to refer all their patients with bleeding disorders, both classified and unclassified, to the designated tertiary care centers. The tertiary health care centers included NIBD and Fatimid Foundation Karachi [FFK] at the province of Sindh, Chughtai's Laboratory and the Children's Hospital Lahore [CHL] at Punjab. Pakistan Atomic Energy Commission Hospital [PAEC] at the federal capital, Islamabad, and Hayatabad Medical Complex [HMC] and Lady Reading Hospital [LRH]) Peshawar at the province of Khyber Pakhtunkhwa [KPK] (Fig. 1). At their visit, patients were enrolled into the current study after acquiring informed written consents. All the non-classified bleeding disorder cases were included into the study. Those categorized as haemophilia A were also included so as to exclude vWD. Patients taking non-steroidal anti-inflammatory drugs (NSAIDS), steroids, clotting factors or those who had had a platelet transfusion 2 weeks prior to the start of the study were excluded.

A general questionnaire, with basic demographic details, clinical and family histories, and the Tosetto bleeding score questionnaire were filled out for each patient by a doctor at the corresponding recruitment center [32]. The doctors were trained before the commencement of the study with administration of the questionnaires.

$8.1 \mathrm{ml}$ venous blood was then collected in three sodium citrate $(0.109 \mathrm{M}, 3.2 \%)$ containing sample collection tubes, each one $2.7 \mathrm{ml}$ in volume. BT, PT, APTT, Factor VIII and IX assays, were determined at the tertiary healthcare centers. In patients with normal platelet count and normal clotting times of PT and APTT, platelet aggregation studies were performed. Peripheral 
A

Patients presenting with bleeding disorders at primary and secondary health care centers/clinics

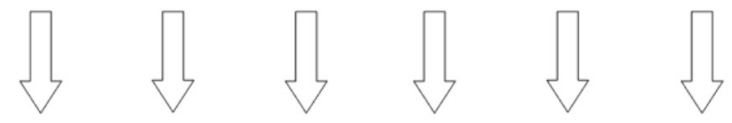

B

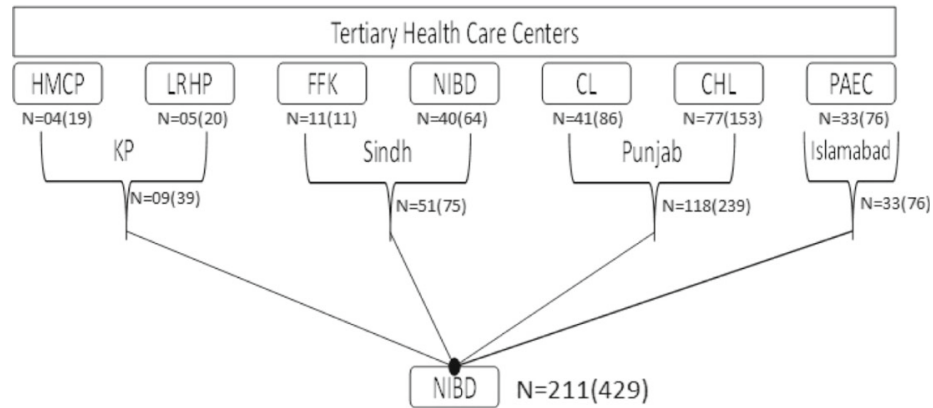

Fig. 1 Flow diagram of patient recruitment, sample collection and its disposition at different levels of health care facilities/laboratories. a Initial presentation of patients with bleeding disorders at primary and/or secondary health care centers. $\mathbf{b}$ Referral of patients to the tertiary health care centers or laboratories for definitive diagnosis. Patients were recruited into the study at this point (c). Samples sent over to the central reference laboratory NIBD where the tests were repeated to establish reliability. CHL, Children Hospital Lahore; CL, Chughtai's Laboratory; FFK, Fatimid Foundation Karachi; HMC, Hayatabad Medical Complex; KP, Khyber Pakhtunkhwa; LRH, Lady Reading Hospital; NIBD, National Institute of Blood Diseases; PAEC, Pakistan Atomic Energy Commission. $\mathrm{N}=$ number of patients with $\mathrm{ARBD}, 0$ indicate total number of patients recruited from each center initially

blood samples were analyzed to identify any platelet morphological abnormalities. The platelet aggregation studies were performed on Helena Aggram platelet aggregometer (Helena laboratory, Beaumont Texas, USA) using standard aggregation reagents (ADP, $2.25 \mu \mathrm{M}$; adrenaline, $5 \mu \mathrm{M}$; collagen, $4 \mu \mathrm{g} / \mathrm{ml}$; ristocetin, $1.5 \mathrm{mg} / \mathrm{ml}$; arachidonic acid, $500 \mu \mathrm{g} / \mathrm{ml}$ ).

An aliquot of the platelet poor plasma, for each patient, was transported to NIBD, the central laboratory, under controlled refrigeration (Fig. 1). Here, the first-line coagulation profile, including PT and APTT were repeated on all the samples, using recombinant tissue factor (Stago, Asnières sur Seine, France). The international normalization ratio (INR) was calculated from the PT using the thromboplastin international sensitivity index (ISI) and the mean normal PT. Fibrinogen levels were measured by Clauss method [33]. Samples with isolated prolonged APTT were further tested for FVIII and factor IX (FIX) using the one stage APTT-based factor assay [34]. If the FVIII and FIX levels were normal then FXI levels were measured (FXI:C). In cases with prolonged PT and APTT, factors II, V and X were tested using an assay based on PT using patient platelet poor plasma, glyoxaline buffer, standard or reference plasma, thromboplastin and calcium. Patients with low levels of FVIII were tested for vWF antigen and vWF ristocetin cofactor. A urea clot solubility test was performed using commercially available thrombin on those patients not diagnosed by other coagulation tests and suspected of having factor XIII deficiency.
To identify the period prevalence for various ARBDs, record from the current study was merged with that from all the studies reported in the last 12 years. For this purpose, the common national (PakMedinet) and international (Pubmed, Google Scholar, ISI Web of science, EMBASE and SCOPUS) databases were screened for studies on ARBDs in Pakistani population.

\section{Results and Discussion}

The study cohort consisted of 429 patients, 250 males and 179 females, with a male to female ratio of 1.3:1. The median age of patients was $11 \pm 5$ years. A history of consanguinity was present in $89 \%$ of cases. Of the 429 patients with diagnosed and suspected bleeding disorders, 211 [49.1\%] were diagnosed to have an ARBD, 116 of these were males and 95 females. Among 95 females, 58 were adult. A majority of patients $(n=148 ; 34.49 \%)$ had hemophilia A while 70 patients remained undiagnosed. Majority of the ARBD patients had VWD type 3 (Table 2).

The most common symptoms reported by the cohort of patients included gum bleeding (57\%), and easy bruising (39\%). Spontaneous epistaxis and gum bleeding were found in $6 \%$, whereas menorrhagia was reported in 19\% of the adult female patients.

Anemia was found in $48 \%$ of the patients. Lifethreatening intracranial hemorrhage affected $4 \%$ of the patients. Phenotypic presentation of ARBDs is detailed in Table 1.

Gum bleeding was more prominent in patients with Glanzmann Thromboasthenia and Bernard-Soulier 
Table 1 Frequency and severity of bleeding

\begin{tabular}{|c|c|c|c|c|c|c|c|c|c|c|c|}
\hline ARBD (N) & Gum Bleeding & Hemarthrosis & Hematoma & Epistaxis & $\begin{array}{l}\text { Menorrhagia }{ }^{c} \\
x / y\end{array}$ & $\begin{array}{l}\text { Umbilical } \\
\text { Cord Bleed }\end{array}$ & $\begin{array}{l}\text { Traumatic } \\
\text { Bleeding }\end{array}$ & Bruises & $\mathrm{ICH}$ & $\mathrm{BG}^{\mathrm{a}}$ & $\mathrm{BS}^{\mathrm{b}}$ \\
\hline WWD-3 (95) & 51 & 8 & 15 & 31 & $11 / 19$ & 10 & - & 12 & - & $\|$ & 13.5 \\
\hline Fib. Def. (34) & 2 & 6 & 17 & 9 & - & - & 23 & 15 & - & $\|$ & 12.5 \\
\hline GT (27) & 23 & - & 4 & 19 & $8 / 9$ & 16 & 27 & 19 & - & $\|$ & 11 \\
\hline FXIII Def. (13) & 11 & - & 6 & 9 & $6 / 6$ & 11 & 5 & 9 & 1 & ॥ & 11.5 \\
\hline FVII Def. (12) & 9 & 8 & 7 & 11 & $6 / 9$ & - & 11 & 9 & 2 & III & 12 \\
\hline FV Def. (9) & 7 & 2 & 6 & 5 & $5 / 7$ & - & 4 & 5 & 1 & ॥ & 11 \\
\hline Vit K Def. (8) & 7 & - & 5 & 2 & $3 / 3$ & 5 & 7 & 5 & - & $\|$ & 12 \\
\hline BSS (7) & 7 & - & 7 & 7 & - & - & 7 & 7 & - & $\|$ & 11 \\
\hline FX Def. (2) & 1 & 2 & 2 & - & $2 / 3$ & 2 & - & & - & $\|$ & 12 \\
\hline FIl Def. (2) & 2 & 1 & 2 & 1 & $1 / 2$ & - & - & 1 & - & $\|$ & 10 \\
\hline FXI Def. (1) & 1 & - & 1 & 1 & - & - & 1 & 1 & - & $\|$ & 10 \\
\hline FV \& FVIII Def. (1) & 1 & 1 & 1 & - & - & - & - & 1 & - & ॥ & 11.5 \\
\hline
\end{tabular}

$\overline{A R B D}$ autosomal recessive bleeding disorders, $B G$ bleeding grade, BS bleeding score, BSS Bernard Soulier syndrome, Def. deficiency, Fib. fibrinogen, FII Factor II, FV Factor V, FVII Factor VII, FX Factor X, FVIII Factor VIII, FXI Factor XI, FXIII Factor XIII, GT Glanzmann Thrombasthenia, ICH intracranial hemorrhage, N number of patients, No. number, Vit vitamin, VWD-3 von Willebrand Disease type 3, $x$ affected females, $y$ females at risk

${ }^{a}$ Calculated on the basis of WHO bleeding grades

based on Tossetto et al bleeding score calculation scale

'Reported in adult female patients only

syndrome; hemarthrosis was most common in patients suffering from factor VII deficiency, hematoma was more noticeable in patients with factor XIII, factor V and vitamin $\mathrm{K}$ dependent clotting factor deficiency. Patients with factor XIII deficiency had the highest incidence of prolonged umbilical cord bleeding. Prolonged bleeding after trauma was associated with factor VII and vitamin $\mathrm{K}$ dependent clotting factor deficiency, GT and BSS. Easy bruising is a prominent feature of GT, BSS and factor XI deficiency according to our study cohort (Table 1).

In the current study, 32 patients were found to have severe fibrinogen deficiency while two patients had moderate severity of the disease. In FXIII deficiency, all the cases had severe disease. Among FVII deficient patients, 2 had mild, 8 had moderate and 2 patients had severe disease. Of the nine patients with FV deficiency, 7 had moderate and 2 had severe disease. All the cases with FX deficiency had severe disease. Two patients had FII deficiency, both bearing moderate severity of the disease. One patient with severe FXI deficiency was also identified. Mild Combined FV \& FVIII deficiency was also found in a single case, as per laboratory phenotype classification [13].

Findings from the current study were compared with those conducted in Italy [35], Iran [35] and India [36], countries with high rates of autosomal recessive diseases due to consanguineous marriages (Fig. 2). In our study patients, vWD type 3 was the most common disorder, with 95 patients (33.8\%), although in a similar,

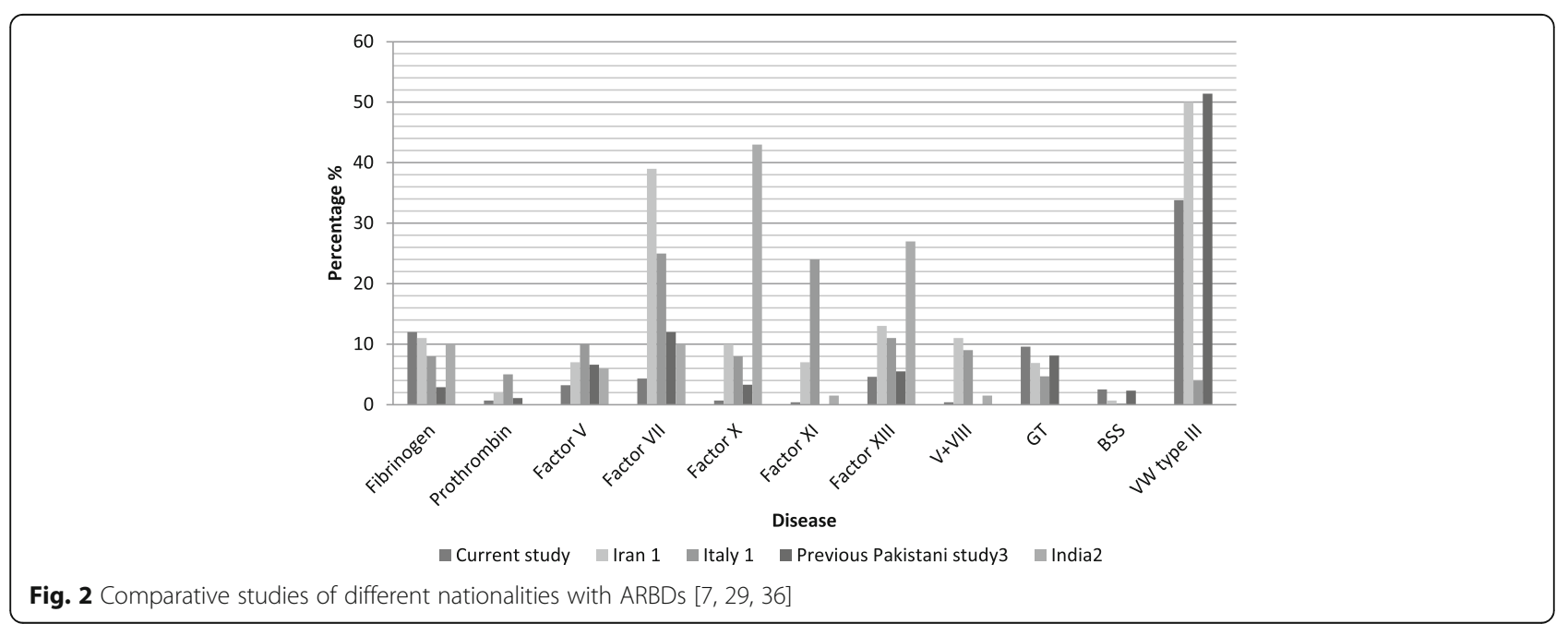


Table 2 Frequency of ARBDs from different provinces of Pakistan

\begin{tabular}{|c|c|c|c|c|c|c|c|c|c|c|}
\hline ARBD & Sindh & Punjab & $\begin{array}{l}\text { Federal } \\
\text { capital }\end{array}$ & KPK & Total & Percentage & $\begin{array}{l}\text { Previously reported cases } \\
\text { from Pakistan" }\end{array}$ & Total & $\begin{array}{l}\text { Local } \\
\text { prevalence } \\
\text { Per million }\end{array}$ & $\begin{array}{l}\text { International } \\
\text { prevalence* } \\
\text { Per million }\end{array}$ \\
\hline WD type 3 disorder & 05 & 62 & 21 & 7 & 95 & $(33.8 \%)$ & 61 & 156 & 1.0 & 0.5 \\
\hline Fibrinogen deficiency & 11 & 20 & 3 & 0 & 34 & $(12 \%)$ & 9 & 43 & 0.3 & 0.5 \\
\hline Glanzmann Thrombasthenia & 18 & 9 & 0 & 0 & 27 & $(9.6 \%)$ & 50 & 77 & 0.5 & 1 \\
\hline Factor XIII deficiency & 7 & 2 & 4 & 0 & 13 & $(4.6 \%)$ & 29 & 42 & 0.3 & 0.5 \\
\hline Factor VII deficiency & 4 & 6 & 1 & 1 & 12 & $(4.3 \%)$ & 84 & 96 & 0.6 & 2 \\
\hline Factor $V$ deficiency & 0 & 9 & 0 & 0 & 9 & $(3.2 \%)$ & 28 & 37 & 0.2 & 1 \\
\hline $\begin{array}{l}\text { Vitamin K dependent clotting } \\
\text { factors deficiency }\end{array}$ & 0 & 7 & 0 & 1 & 8 & $(2.8 \%)$ & 0 & 8 & 0.04 & 1 \\
\hline Bernard Soulier syndrome & 3 & 0 & 4 & 0 & 7 & $(2.5 \%)$ & 5 & 12 & 0.07 & 1 \\
\hline Factor $X$ deficiency & 1 & 1 & 0 & 0 & 2 & $(0.7 \%)$ & 41 & 43 & 0.3 & 1 \\
\hline Factor II deficiency & 0 & 2 & 0 & 0 & 2 & $(0.7 \%)$ & 10 & 12 & 0.07 & 0.5 \\
\hline Factor XI deficiency & 1 & 0 & 0 & 0 & 1 & $(0.4 \%)$ & 1 & 2 & 0.01 & $1 \sim$ \\
\hline $\begin{array}{l}\text { Combined Factor V \& VIII } \\
\text { deficiency }\end{array}$ & 1 & 0 & 0 & 0 & 1 & $(0.4 \%)$ & 0 & 1 & 0.006 & 1 \\
\hline
\end{tabular}

There were no patients from the province of Baluchistan, Gilgit Baltistan and Azad Jammu \& Kashmir due to lack of health and diagnostic facilities

* International prevalence data from world hemophilia database and orphanet journal of rare diseases

$\sim$ Frequency is 1 in 450 in Ashkenazi Jews

" $[6,37,38]$

Period Prevalence calculations were based on CDC formulation

local study, the percentage was $51.4 \%$ [7], in Iran it was $50 \%$ [35], and in Italy, just $4 \%$ [35]. It is hence concluded that in south Asian population vWD type 3 has a high frequency among ARBDs. The second most common deficiency found in this study was fibrinogen deficiency $(n=34,12 \%)$. The disease was found to have a frequency of $11 \%$ in the Iranian study [35], $8 \%$ in the Italian study [35] and $10 \%$ in the Indian study [36]. Our study findings are comparable to those from the mentioned contemporary studies. GT, a relatively well understood platelet disorder, was diagnosed in 27 (9.6\%) of patients. Its frequency was $6.9 \%$ in the Iranian study, $4.7 \%$ in the Italian study, and $8.1 \%$ in an earlier Pakistani study (Fig. 2).

South Asian countries, particularly Pakistan, have a high frequency of consanguineous partnerships [4], which explains the increased prevalence of ARBD in this region. The local 12 years period prevalence of ARBDs [37, 38] compared with the international prevalence is shown in Table 2. Data was not available from the Baluchistan, Gilgit-Baltistan and Azad Kashmir regions. A larger national study is needed to cover the underprivileged, difficult to access areas of Pakistan, not included in the current study due to the poorly structured healthcare system and difficulties with law and order in these regions. Worldwide data has clearly shown that there is variation in the prevalence of individual ARBDs. Genetic studies to identify the underlying mutations would help in understanding the phenotype/genotype relationship.
There is also a need to educate the general population regarding the risks of ARBDs and to initiate genetic counseling services to help prevent consanguineous marriage in families with a history of these disorders. Patients with ARBDs require lifelong management and education on lifestyle modifications relevant to the bleeding disorder that they live with.

\section{Conclusion}

These data have shown that vWD type 3 has the highest incidence amongst the ARBDs in this study cohort, followed by fibrinogen deficiency. GT was found to be the third most common disorder. The incidence of ARBDs in this region is higher than previously thought.

\section{Abbreviations}

APTT: Activated partial thromboplastin time; ARBDs: Autosomal recessive bleeding disorders; BT: Bleeding time; CFD: Clotting factor deficiency; GT: Glanzmann's thrombasthenia; NIBD: National Institute of Blood Diseases and Bone Marrow Transplantation; PFD: Platelet functional disorder; PT: Prothrombin time; VKCFD: Vitamin K-dependent clotting factor deficiency; VWD: von Willebrand disease

\section{Acknowledgements}

We wish to thank Dr Shehla Tariq for providing access to patient information, Dr Nauman Malik and Hafiz Rafiq for laboratory assistance, Dr Nazish Saqlain and Dr Salwa Paracha for interviewing the patients from Lahore. We also thank Dr Shahtaj Masood for providing laboratory diagnostic support from HMC Peshawar and Mahmood Khan for giving laboratory diagnostic support from Islamabad. We are also grateful to Aqsa from Children's Hospital, Lahore for laboratory diagnostic workup, and to Abdul Malik Khan and Asif Khan for providing computer data input from NIBD. 


\section{Funding}

The funding has been provided by the Novo Nordisk foundation. However the foundation was not responsible for the study design, interpretation of data and manuscript writing.

\section{Availability of data and materials}

The raw data and all the relevant information is accessible upon request.

\section{Authors' contributions}

AN designed and supervised the study, overseeing the data collection, interpretation, management, statistical analysis and drafting of the article for this study. MYJ was involved in writing the manuscript. SA was the study coordinator and was involved in the collection of clinical information and diagnostic interpretation of bleeding disorder results from Islamabad region. IU was the study coordinator. He was responsible for the collection of clinical data and diagnostic information of platelet disorder patients from Sindh. AND was the study coordinator. He was responsible for the collection of clinical data and diagnostic information of platelet disorder patients from Karachi. HP received blood samples, provided laboratory analysis and summarized the diagnostic data. NA and Al were responsible for collection of clinical information and diagnostic interpretation of bleeding disorder results. They were the study coordinators from Lahore. FR was the study coordinator from Peshawar. He was responsible for the collection of clinical data and diagnostic interpretation of bleeding disorder results from this region. TSS was the team leader, secured funding for this project, provided training sessions for clinicians to investigate and manage bleeding disorders throughout country. All authors read and approved the final manuscript.

\section{Competing interests}

All the authors declare that they have no competing interests.

\section{Consent for publication}

\section{Not applicable.}

\section{Ethics approval and consent to participate}

The Institutional Ethics committee has reviewed and approved to conduct the above mentioned cross sectional study conducted by the Department of Thrombosis \& Hemostasis. ETHICAL COMMITTEE AND IRB NIBD Date: 05th March 2010 IRB/IEC Ref No. : 87/NIBD. Members include Dr Nazli Hussain, Dr Tahir S. Shamsi and Dr Tasneem Farzana.

The study questionnaire and consent forms have been duly attained from the participants, which permit the presentation and publication of the data as and when necessary for the benefit of the scientific community.

\section{Publisher's Note}

Springer Nature remains neutral with regard to jurisdictional claims in published maps and institutional affiliations.

\section{Author details}

${ }^{1}$ Department of Thrombosis and Hemostasis, National Institute of Blood Diseases and Bone Marrow Transplantation, ST 2/A, Block 17, Gulshan-e-lqbal, KDA Scheme 24, Karachi, Pakistan. ²Department of Hematology, Pakistan Atomic Energy Commission Hospital, Islamabad, Pakistan. ${ }^{3}$ Department of Pathology, Liaquat University of Medical and Health Sciences, Jamshoro, Pakistan. ${ }^{4}$ Fatimid Foundation, Karachi, Pakistan. ${ }^{5}$ Department of Hematology, Hayatabad Medical Complex and Lady Reading Hospital, Peshawar, Pakistan. ${ }^{6}$ Department of Hematology, Children's Hospital, Lahore, Pakistan.

${ }^{7}$ Department of Hematology, Chughtai's Laboratory, Lahore, Pakistan.

Received: 11 July 2016 Accepted: 28 March 2017

Published online: 07 April 2017

\section{References}

1. Peyvandi F, Palla R, Menegatti M, Mannucci PM. Introduction: rare bleeding disorders: general aspects of clinical features, diagnosis, and management. Semin Thromb Hemost. 2009;35(4):349-55. (c) Thieme Medical Publishers.

2. Peyvandi F, Spreafico M. National and international registries of rare bleeding disorders. Blood Transfus. 2008;6 Suppl 2:545-8.

3. Bhopal RS, Petherick ES, Wright J, Small N. Potential social, economic and general health benefits of consanguineous marriage: results from the Born in Bradford cohort study. Eur J Public Health. 2014;24(5):862-9.
4. Hussain R, Bittles AH. The prevalence and demographic characteristics of consanguineous marriages in Pakistan. J Biosoc Sci. 1998;30(2):261-75. Epub 1998/09/25

5. Qidwai W, Syed IA, Khan FM. Prevalence and perceptions about consanguineous marriages among patients presenting to family physicians, in 2001 at a Teaching Hospital in Karachi, Pakistan. Asia Pac Fam Med. 2003;2(1):27-31.

6. Borhany M, Pahore Z, ul Qadr Z, Rehan M, Naz A, Khan A, et al. Bleeding disorders in the tribe: result of consanguineous in breeding. Orphanet J Rare Dis. 2010;5(1):1.

7. Borhany M, Shamsi T, Fatima N, Fatima H, Naz A, Patel H. Rare bleeding disorders are not so rare in Pakistan. J Hematol Thromboembolic Dis. 2014;2014.

8. Borhany M, Shamsi T, Naz A, Farzana T, Ansari S, Nadeem M, et al. Clinical features and types of von Willebrand disease in Karachi. Clin Appl Thromb Hemost. 2011:17(6):E102-5.

9. Borhany M, Shamsi T, Naz A, Khan A, Parveen K, Ansari S, et al. Congenital bleeding disorders in Karachi, Pakistan. Clin Appl Thromb Hemost. 2011; 17(6):E131-7.

10. Fadoo Z, Saleem AF. Factor XIII deficiency in children-clinical presentation and outcome. J Coll Physicians Surg Pak. 2008;18(9):565.

11. Khan MK, Khan SQ, Malik NA. Spectrum of Von Willebrand's disease in Punjab: clinical features and types. J Ayub Med Coll Abbottabad. 2014;26(4):470.

12. Peyvandi F, Palla R, Menegatti M, Siboni S, Halimeh S, Faeser B, et al. Coagulation factor activity and clinical bleeding severity in rare bleeding disorders: results from the European Network of Rare Bleeding Disorders. J Thromb Haemost. 2012;10(4):615-21.

13. Peyvandi F, Di Michele D, Bolton-Maggs P, Lee C, Tripodi A, Srivastava A. Classification of rare bleeding disorders (RBDs) based on the association between coagulant factor activity and clinical bleeding severity. J Thromb Haemost. 2012:10(9):1938-43.

14. Tziomalos K, Vakalopoulou S, Perifanis V, Garipidou V. Treatment of congenital fibrinogen deficiency: overview and recent findings. Vasc Health Risk Manag. 2009;5:843-8.

15. De Moerloose $P$, Casini A, Neerman-Arbez M. Congenital fibrinogen disorders: an update. Semin Thromb Hemost. 2013;39(06):585-95. (c) Thieme Medical Publishers.

16. Lancellotti S, Basso M, De Cristofaro R. Congenital prothrombin deficiency: an update. Semin Thromb Hemost. 2013;39(06):596-606. ( ) Thieme Medical Publishers.

17. Huang J, Koerper M. Factor V deficiency: a concise review. Haemophilia. 2008;14(6):1164-9.

18. Mariani G, Bernardi F. Factor VII deficiency. Semin Thromb Hemost. 2009; 35(4):400-6. ( Thieme Medical Publishers.

19. Lak M, Peyvandi F, Mannucci P. Clinical manifestations and complications of childbirth and replacement therapy in 385 Iranian patients with type 3 von Willebrand disease. Br J Haematol. 2000;111(4):1236-9.

20. Zhang B, McGee B, Yamaoka JS, Guglielmone H, Downes KA, Minoldo S, et al. Combined deficiency of factor $V$ and factor $V I I I$ is due to mutations in either LMAN1 or MCFD2. Blood. 2006:107(5):1903-7.

21. Karimi M, Cairo A, Safarpour MM, Haghpanah S, Ekramzadeh M, Afrasiabi A, et al. Genotype and phenotype report on patients with combined deficiency of factor $V$ and factor VIII in Iran. Blood Coagul Fibrinolysis. 2014;25(4):360-3.

22. Spreafico M, Peyvandi F. Combined factor V and factor VIII deficiency. Semin Thromb Hemost. 2009:35(4):390-9. @ Thieme Medical Publishers.

23. Weston BW, Monahan PE. Familial deficiency of vitamin K-dependent clotting factors. Haemophilia. 2008;14(6):1209-13.

24. Menegatti M, Peyvandi F. Factor X deficiency. Semin Thromb Hemost. 2009; 35(4):407-15. (c) Thieme Medical Publishers.

25. Gomez K, Bolton-Maggs P. Factor XI deficiency. Haemophilia. 2008;14(6): 1183-9. Epub 2008 Feb.

26. Hsieh L, Nugent D. Factor XIII deficiency. Haemophilia. 2008;14(6):1190-200.

27. Muszbek L, Katona É. Diagnosis and management of congenital and acquired FXIII deficiencies. Semin Thromb Hemost. 2016:42(04):429-39. (c)Thieme Medical Publishers.

28. Nurden AT Glanzmann thrombasthenia. Orphanet J Rare Dis. 2006:1(1):1.

29. Nurden AT, Pillois X, Nurden P. Understanding the genetic basis of Glanzmann thrombasthenia: implications for treatment. Expert Rev Hematol. 2012;5(5):487-503.

30. Lanza F. Bernard-Soulier syndrome (hemorrhagiparous thrombocytic dystrophy). Orphanet J Rare Dis. 2006;1(1):1. 
31. Andrews RK, Berndt MC. Bernard-Soulier syndrome: an update. Semin Thromb Hemost. 2013;39(06):656-62. @Thieme Medical Publishers.

32. Tosetto A, Castaman G, Plug I, Rodeghiero F, Eikenboom J. Prospective evaluation of the clinical utility of quantitative bleeding severity assessment in patients referred for hemostatic evaluation. J Thromb Haemost. 2011;9(6):1143-8.

33. Acharya S, Dimichele D. Rare inherited disorders of fibrinogen. Haemophilia. 2008;14(6):1151-8

34. Kirkwood T, Snape T. Biometric principles in clotting and clot lysis assays. Clin Lab Haematol. 1980;2(3):155-67.

35. Mannucci PM, Duga S, Peyvandi F. Recessively inherited coagulation disorders. Blood. 2004;104(5):1243-52.

36. Sharma SK, Kumar S, Seth T, Mishra P, Agrawal N, Singh G, et al. Clinical profile of patients with rare inherited coagulation disorders: a retrospective analysis of 67 patients from Northern India. Mediterr J Hematol Infect Dis. 2012;4(1):e2012057.

37. Khalid S, Bilwani F, Adil SN, Khurshid M. Frequency and clinical spectrum of rare inherited coagulopathies-a tricenter study. J Pak Med Assoc. 2008;58(8):441.

38. Zaidi A, Anwar K, Alam I. Pattern of hereditary coagulation disorders in northern areas of Pakistan. J Postgrad Med Institute (Peshawar-Pakistan). 2011;13(1):26-30.

Submit your next manuscript to BioMed Central and we will help you at every step:

- We accept pre-submission inquiries

- Our selector tool helps you to find the most relevant journal

- We provide round the clock customer support

- Convenient online submission

- Thorough peer review

- Inclusion in PubMed and all major indexing services

- Maximum visibility for your research

Submit your manuscript at www.biomedcentral.com/submit
C) Biomed Central 